\title{
Robustness of the dynamic visual movement effect
}

\author{
WILLIAM W. AGRESTI \\ University of Michigan, Dearborn, Michigan 48128 \\ and \\ MARK S. MAYZNER \\ Loyola University, Chicago, Illinois 60626
}

\begin{abstract}
The present study examines further the effects of certain selected spatiotemporal parameters on dynamic visual movement. The results suggest that the subjectively perceived number of inputs is highly sensitive to the spatiotemporal ordering of the input array.
\end{abstract}

As a part of a continuing study of complex spatiotemporal interactions in the human visual system, the phenomenon of dynamic visual movement was first reported in 1970 (Mayzner \& Tresselt, 1970). Using a computer-based cathode-ray tube (CRT) display system, a particular pattern of presenting characters on the CRT evoked a consistent response from subjects that the characters appeared to be moving across the screen. That display consisted of 20 letter Os that were placed next to each other across the screen. However, the timing and ordering of the individual character presentations was critical. Each letter was displayed for $5 \mathrm{msec}$ (the "on time"), and then an interval of $5 \mathrm{msec}$ (the "off time") elapsed before the next character was displayed. Further, the order in which the letters were displayed was as follows: $1,5,9,13,17,2,6,10,14,18,3,7,11,15$, $19,4,8,12,16,20$. That is, the leftmost letter was presented first for $5 \mathrm{msec}$ (i.e., 1); then, after $5 \mathrm{msec}$ of off time, the sixth letter from the left was presented for $5 \mathrm{msec}$ (i.e., 2), and so on. The entire display was cycled continuously. Subjects reported seeing four letter Os spaced equally apart and in continuous smooth movement from left to right across the screen. The effect was likened to "ducks in a shooting gallery."

The four Os in apparent movement would appear to correspond to the four spatiotemporal groupings $1,5,9$, 13,17 , followed by $2,6,10,14,18$, followed by 3,7 , $11,15,19$, followed by $4,8,12,16,20$. Recalling the 5 -msec on time and 5-msec off time, then within each group, $35 \mathrm{msec}$ elapsed between adjacent inputs; for example, between inputs 1 and 5, 5 and 9, and so on.

The present study deals with the robustness of this dynamic visual movement effect under widely varying display orderings. Using the display order of the earlier study as a guide, seven different orderings were designed to support the movement of $2,3,4,6,9,12$, or 18

This research was supported in part by National Science Foundation Grants GB-22785 and BNS75-09800 A02 to M. S. Mayzner. characters, respectively, in a line of 36 . Because the on times and off times are varied as well, the spatiotemporal patterns thus produced are very complex. We are interested in identifying those combinations for which the subject reports dynamic visual movement.

\section{METHOD}

The five subjects were all graduate student volunteers. The stimuli were presented on a VR-14 CRT display connected to a PDP 8/E computer. The CRT display surface was coated with an ultrashort-persistence phosphor (i.e., a P24). A detailed description of this laboratory can be found in Mayzner $(1968,1975)$.

The stimuli consisted of 36 letter Xs arranged in a straight line across the display surface. Display luminance was $1 \mathrm{~mL}$. The subject was seated $2 \mathrm{ft}$ in front of the display screen. The $36 \mathrm{Xs}$ were presented under seven different orderings, shown in Table 1. These particular orderings were chosen to assess whether they correspond to $2,3,4,6,9,12$, or 18 moving Xs, respectively. There were five different presentation times used: $1,3,5,7$, and $9 \mathrm{msec}$. These times represent both the on time

Table 1

Display Orderings

\begin{tabular}{|c|c|}
\hline $\begin{array}{l}\text { Group- } \\
\text { ing }\end{array}$ & Order of Presentation \\
\hline 2 & $1,3,5,7,9, \ldots 35, / 2,4,6,8,10, \ldots 36, /$ \\
\hline 3 & $1,4,7,10, \ldots 34, / 2,5,8,11, \ldots 35, / 3,6,9,12, \ldots 36$, \\
\hline 4 & $\begin{array}{l}1,5,9, \ldots 33, / 2,6,10, \ldots 34, / 3,7,11, \ldots 35, / \\
4,8,12, \ldots 36, /\end{array}$ \\
\hline 6 & $\begin{array}{l}1,7,13, \ldots 31, / 2,8,14, \ldots 32, / 3,9,15, \ldots 33, / \\
4,10,16, \ldots 34, / 5,11,17, \ldots 35, / 6,12,17, \ldots 36 /\end{array}$ \\
\hline 9 & $\begin{array}{l}1,10,19, \ldots 28, / 2,11,20, \ldots .29, / 3,12,21, \ldots 30, / \\
4,13,22, \ldots 31, / 5,14,23, \ldots 32, / 6,15,24, \ldots 33, / \\
7,16,25, \ldots 34, / 8,17,26, \ldots 35, / 9,18,27, \ldots 36 /\end{array}$ \\
\hline 12 & $\begin{array}{lrrrr}1,13,25, / & 2,14,26, / / & 3,15,27, / & 4,16,28, / & 5,17,29, / \\
6,18,30, / & 7,19,31, / & 8,20,32, / & 9,21,32, / & 9,21,33, / \\
10,22,34, / & 11,23,35, / & 12,24,36 / & & \end{array}$ \\
\hline 18 & $\begin{array}{lllllll}1,19 / & 2,20 / 3,21 / 4,22 / 5,23 / & 6,24 / 7,25 / & 8,26 / \\
9,27 / & 10,28 / 11,29 / 12,30 / & 13,31 / & 14,32 / & 15,33 / \\
16,34 / 17,35 / 18,36 /\end{array}$ \\
\hline
\end{tabular}

Note-Grouping refers to the number of moving $X$ s. 
Table 2

Mean Number of Xs Seen at One Time

\begin{tabular}{cccccc}
\hline \multirow{2}{*}{$\begin{array}{c}\text { Group- } \\
\text { ing }\end{array}$} & \multicolumn{5}{c}{ On-Time (in Milliseconds) } \\
\cline { 2 - 6 } & 1 & 3 & 5 & 7 & \multicolumn{1}{c}{9} \\
\hline 2 & 36.00 & 34.68 & 9.28 & 2.40 & 2.40 \\
3 & 36.00 & 21.32 & 3.28 & 3.28 & 3.08 \\
4 & 36.00 & 14.36 & 4.56 & 4.28 & 4.24 \\
6 & 36.00 & 12.00 & 6.20 & 6.20 & 6.00 \\
9 & 36.00 & 18.12 & 9.00 & 9.00 & 9.00 \\
12 & 36.00 & 16.32 & 11.92 & 12.00 & 12.00 \\
18 & 36.00 & 29.84 & 18.00 & 18.00 & 18.00 \\
\hline
\end{tabular}

Note-Grouping refers to the number of moving $X$ s.

Table 3

Elapsed Time in Milliseconds Between Adjacent Xs Within a Group

\begin{tabular}{cccccc}
\hline \multirow{2}{*}{$\begin{array}{c}\text { Group- } \\
\text { ing }\end{array}$} & \multicolumn{5}{c}{ On-Time (in Milliseconds) } \\
\cline { 2 - 6 } & 1 & 3 & 5 & 7 & \multicolumn{1}{c}{9} \\
\hline 2 & 3 & 9 & 15 & 21 & 27 \\
3 & 5 & 15 & 25 & 35 & 45 \\
4 & 7 & 21 & 35 & 49 & 63 \\
6 & 11 & 33 & 55 & 77 & 99 \\
9 & 17 & 51 & 85 & 119 & 153 \\
12 & 23 & 69 & 115 & 161 & 207 \\
18 & 35 & 105 & 175 & 245 & 315 \\
\hline
\end{tabular}

Note-Grouping refers to the number of moving $X$ s.

for each letter and the off time before the next lette appeared. For each time-ordering combination, there were five replications. The order of the presentations was randomized over time and ordering so that each subject was presented with $7 \times 5 \times 5=175$ displays. The subject was asked to report how many Xs he saw at any instant and was told that the entire line consisted of $36 \mathrm{Xs}$.

\section{RESULTS}

Table 2 gives the mean number of Xs seen at one time at each combination of grouping and on time. There is a relationship between the number of Xs reported by the subject and the strength of the movement effect. For example, if the grouping supported six moving $\mathrm{Xs}$ and the subject reported seeing six Xs at one time, this response was interpreted as the strongest verification of dynamic visual movement.

From Table 2 it is clear that $1 \mathrm{msec}$ was too short to promote the movement effect, with all subjects reporting seeing all $36 \mathrm{Xs}$ at one time no matter what grouping was imposed. At $3 \mathrm{msec}$, all of the entries in Table 2 lie between 36 and the target number of moving Xs for that grouping. With an on time of $5 \mathrm{msec}$, dynamic visual movement appears to be established for groupings of three or more, because the entries in that column are close to the target number of the grouping. The single exception is two moving $\mathrm{Xs}$ at $5 \mathrm{msec}$, in which the mean number seen $(9.28)$ is clearly too high.

The evidence for dynamic visual movement is strongest for those combinations in the lower right-hand quadrant of Table 2.

\section{DISCUSSION}

In the original report of dynamic visual movement (Mayzner \& Tresselt, 1970), the elapsed time between presentation of adjacent characters within a group was $35 \mathrm{msec}$. Table 3 gives the elapsed times for the various combinations in the present experiment. When considering Tables 2 and 3 together, it appears that elapsed times as much as nine times greater than 35 still promote the movement effect. The elapsed times in the lower right-hand quadrant of Table 3, where dynamic visual movement was most pronounced, are all significantly higher than $35 \mathrm{msec}$.

Dynamic visual movement is also sensitive to the on time alone. Table 2 shows that on times of 1 and $3 \mathrm{msec}$ are too short to promote the effect, despite the fact that some of the elapsed times for those combinations (from Table 3) are well within range.

Evidence of the effect was obtained under all seven groupings (Table 2). This finding greatly extends the earlier result (Mayzner \& Tresselt, 1970).

Perhaps most surprising is the strength of dynamic visual movement for 18 moving Xs. In such cases, recall from Table 1 that the "path" of each letter is very short. The appearance of motion is achieved by only one reinforcement, that being the presentation of the second letter in an adjacent position a fraction of a second later. It seems remarkable that such a spatiotemporal pattern would be organized by the visual system in this way. This grouping of 18 moving Xs in a line of 36 would seem to be one of a class of "minimal" patterns that would elicit reports of dynamic visual movement. It contains only two stimuli, the starting and ending points, with no opportunity to reinforce the apparent movement in between.

\section{REFERENCES}

MAYZnER, M. S. The research potential of a computer-based cathode-ray tube display system. Behavior Research Methods \& Instrumentation, 1968, 1, 41-43.

MAYZNER, M. S. Studies in risual information processing in man. In $R$. Solso (Ed.), Information processing and cognition: The Loyola symposium. Hillsdale, N.J: Lawrence Erlbaum, 1975. Chapter 2, pp. 31-54.

Mayzner, M. S., \& Tresselt, M. E. Visual dynamics of a novel apparent movement effect. Psychonomic Science, $1970,18,331-332$.

(Received for publication May 1, 1978.) 